\title{
Review: self help interventions alone minimally increase smoking cessation
}

\author{
Lancaster T, Stead LF. Self-help interventions for smoking cessation. (Cochrane Review, latest version 26 Aug 98). In: Cochrane Library. \\ Oxford: Update Software.
}

\section{Question}

What is the effectiveness of self help smoking cessation interventions?

\section{Data sources}

Studies were identified by searching the Tobacco Addiction Review Group Register (which includes studies identified from Medline, PsycLIT, Dissertation Abstracts Online, Applied Social Sciences Index and Abstracts, Social Citations Index, and Social Science Citations Index) using the terms self-help, manual, and booklet; and bibliographies of previous reviews.

\section{Study selection}

Randomised or quasi-randomised controlled trials were selected if they had $\geqslant 6$ months follow up and if $\geqslant 1$ treatment arm involved a self help intervention without repeated face to face contact with a therapist. Self help interventions had to involve a structured programme for quitting. Studies of pregnant women were excluded.

\section{Data extraction}

Data were extracted on the study population, method of randomisation, type of intervention, follow up, and validation of self reported cessation.

\section{Main results}

Meta-analysis of 10 trials of self help compared with no self help found no clear differences for smoking cessation at longest follow up $(\mathrm{p}=0.06)$ (table). When 3 trials in which the control group received some form of leaflet were excluded from the analysis, the self help group had slightly higher smoking cessation rates $(\mathrm{p}<0.04)$ (table). Adding self help to advice or to nicotine replacement therapy did not increase smoking cessation. Several studies assessed enhancements to self help interventions. Meta-analysis of 6 studies showed that personalised self help materials increased smoking cessation compared with standard materials $(6.2 \% v 4.3 \%$, relative benefit increase [RBI] 49\%, 95\% CI 12 to 98). Meta-analysis of 6 studies showed that self help materials with telephone follow up increased smoking cessation (11.4\% v 7.9\%, RBI 55\%, CI 30 to 85 ).

\section{Conclusions}

Self help interventions alone minimally increase smoking cessation rates. Self help materials added to nicotine replacement therapy or to advice do not confer additional benefits. Self help interventions that are personalised to individual smokers, or are supplemented with telephone follow up, improve smoking cessation.

Self help $v$ no self help for smoking cessation at longest follow up (range 6 to $24 \mathrm{mo}^{*}$ *

\begin{tabular}{lllll}
\hline \multirow{4}{*}{$\begin{array}{l}\text { Number of } \\
\text { studies }\end{array}$} & \multicolumn{2}{l}{ Weighted event rates } & & \\
\cline { 2 - 4 } & Self help & No self help & RBI (95\% CI) & NNT (CI) \\
\hline 10 & $5.1 \%$ & $4.5 \%$ & $8 \%(-8$ to 27$)$ & Not significant \\
$7 \dagger$ & $4.3 \%$ & $3.5 \%$ & $27 \%(2$ to 58$)$ & $123(64$ to 1771$)$
\end{tabular}

*Abbreviations defined in glossary. RBI, NNT, and CI calculated from data in article. $\dagger$ Control group received no written materials.

Source of funding: National Health Service and Imperial Cancer Research Fund.

For correspondence: Mrs Lindsay Stead, ICRF General Practice Research Group, Division of Public Health and Primary Health Care, Institute of Health Sciences, Old Road, Headington, Oxford OX3 7LF, UK. Fax $+44(0) 1865227137$

Abstract and modified commentary also published in ACP Journal Club, and modified abstract also published in Evidence-Based Nursing.

\section{Commentary}

Lancaster and Stead did a concise review of the randomised controlled trials of smoking cessation self help materials. They conclude that self help materials have limited benefit, but may still play a part in smoking cessation programmes.

Self help materials are a low intensity intervention and should not be expected to be very effective. For smoking cessation, self help materials are somewhat beneficial when tailored to a person's readiness to quit or when used in conjunction with telephone follow up. Self help materials have no benefit if mailed or when added to the advice of a healthcare professional in the clinical setting.

What part do self help materials play in the mental health clinic? For patients who are not ready to quit, the materials can motivate an attempt to quit between clinic visits. For the patients who are ready to quit, the materials can reinforce the mental health worker's behavioural therapy and provide reinforcement of the cessation instructions. Although some experts recommend that all people who smoke should receive nicotine replacement therapy, ${ }^{1}$ self help materials may be sufficient for motivated people who are light smokers, and are much less expensive than medication therapy. ${ }^{2}$ Because of the interplay between nicotine and psychiatric conditions, patients with mental illness may require intensive treatment consisting of both behavioural therapy and medication. ${ }^{3}$ The bottom line of this review is that you should not expect self help materials to be successful on their own.

\section{Eric C Westman, MD, MHS \\ Duke University and Durham VA Medical Center Durham, North Carolina,}

USA

1 The Agency for Health Care Policy and Research Smoking Cessation Clinical Practice Guideline. JAMA 1996;275:1270-80.

2 Silagy C, Mant D, Fowler G, et al. Nicotine replacement therapy for smoking cessation. (Cochrane Review, latest version 21 May 98). In: Cochrane Library. Oxford: Update Software.

3 American Psychiatric Association Practice American Psychiatric Association. Practice guideline for the treatment of patients with 153(suppl 10):1-31. 